\title{
Magnetization intensity mapping on Unzen Volcano, Japan, determined from high-resolution, low-altitude helicopter-borne aeromagnetic survey
}

\author{
Ayako Okubo $^{1}$, Yoshikazu Tanaka ${ }^{2}$, Mitsuru Utsugi ${ }^{2}$, Naoto Kitada $^{2}$, Hiroshi Shimizu ${ }^{3}$, and Takeshi Matsushima ${ }^{3}$ \\ ${ }^{1}$ Disaster Prevention Research Institute, Kyoto University, Kyoto 611-0011, Japan \\ ${ }^{2}$ Institute for Geothermal Sciences Graduate School of Science, Kyoto University, Kumamoto 869-1404, Japan \\ ${ }^{3}$ Institute of Seismology and Volcanology, Faculty of Sciences, Kyushu University, Nagasaki 855-0843, Japan
}

(Received January 29, 2004; Revised June 30, 2004; Accepted July 12, 2004)

\begin{abstract}
On September 18, 2002, we conducted a high-resolution, low-altitude helicopter-borne aeromagnetic survey at two flight altitudes, using spiral trajectories for the first time, over Unzen Volcano in the framework of the Unzen Scientific Drilling Project (USDP). This study obtained more detailed and new information than the previous aeromagnetic studies in Unzen volcano about the geological features, for understanding the history and eruption mechanism of the Unzen volcano. Therefore, we conducted a magnetization intensity mapping on the volcano, on the assumption that the magnetic anomalies are caused by the terrain magnetized in the same direction as the present Earth's magnetic field and the magnetization intensity varies only laterally. This map shows good agreement with the geologic features, especially the hydrothermal alteration zone and the collapsed pyroclastic deposits. In addition, even in the area covered by lavas, the magnetization intensities show various values corresponding to each eruption event. It may be considered that the differences in magnetic properties reflect different oxygen fugacity in rocks during their cooling time period. Local magnetization lows on HeiseiShinzan suggest that the Heisei lava produced by the 1991-1995 eruption has not yet been cooled enough.
\end{abstract}

Key words: Aeromagnetic survey, Unzen volcano, magnetization intensity mapping.

\section{Introduction}

Unzen volcano (Fig. 1) is an active composite volcano, located on the Shimabara Peninsula, in the western extremity of a large graben across Central Kyushu, Japan. Almost all lava domes and eruptive centers are distributed within the "Unzen Graben" bounded by E-W trending faults, such as the Chijiwa, Kanahama and Futsu.

Unzen volcano began phreatic eruptions in November, 1990 at the summit craters after quiescence of 198 years. After intensive ash ejection in February 1991, a lava dome appeared on the eastern flank of Mt. Fugen in May, 1991. The lava dome, named Heisei-Shinzan, gradually grew and yielded frequent pyroclastic flows until the eruptive activity ended in 1995.

Because of the strong and variable magnetizations of volcanic terrain, magnetic surveys are often used to map flows and hydrothermally altered rocks (Okuma et al., 1994, 1998; Finn and Morgan, 2002). In order to better characterize the volcanic history of this active volcano, several previous magnetic surveys were conducted. Nakatsuka (1994) found a characteristic graben structure filled with volcanics and an old volcanic unit unknown around Sarubayama from a high-altitude aeromagnetic survey at 7,500 feet with a line spacing of about $500 \mathrm{~m}$. Although the results provided information on regional-scale structures, local detailed geologic information on the volcano was lacking. The blimp-

Copyright (c) The Society of Geomagnetism and Earth, Planetary and Space Sciences (SGEPSS); The Seismological Society of Japan; The Volcanological Society of Japan; The Geodetic Society of Japan; The Japanese Society for Planetary Sciences; TERRAPUB borne magnetic survey by Honkura et al. (1995) did not cover the entire Unzen Volcano and positioning data were not very accurate. Another previous low-altitude aeromagnetic survey over the target area (Mogi et al., 1995) did not include the Heisei-Shinzan area.

In the framework of the Unzen Scientific Drilling Project (USDP), we conducted a high-resolution low-altitude aeromagnetic survey at two flight altitudes using spiral trajectories with good positioning accuracy over Unzen volcano including Heisei-Shinzan. For detailed analyses and interpretations of the magnetic anomalies, we mapped the magnetization intensity on the volcano using the aeromagnetic anomalies at both altitudes. In this paper, we discuss the relation between our results and the geology of the volcano and provide more detailed and new information to improve understanding of the history of volcanic activity and the eruption mechanism of Mt. Unzen.

\section{Geological Setting}

Hoshizumi et al. (1999) discussed the eruptive history of Unzen volcano basing on the geological map of Unzen volcano by Watanabe and Hoshizumi (1995) and newly obtained ages data. According to Hoshizumi et al. (1999) (Fig. 2), we summarize the geology of Unzen Volcano as follows.

Unzen volcano has erupted to bring lavas and pyroclastic products of andesite to dacite composition and has developed a volcanotectonic graben during the past 500 thousand years. The volcano can be divided into the Older (mainly 300-200 ka) and Younger (<100 ka) Unzen vol- 


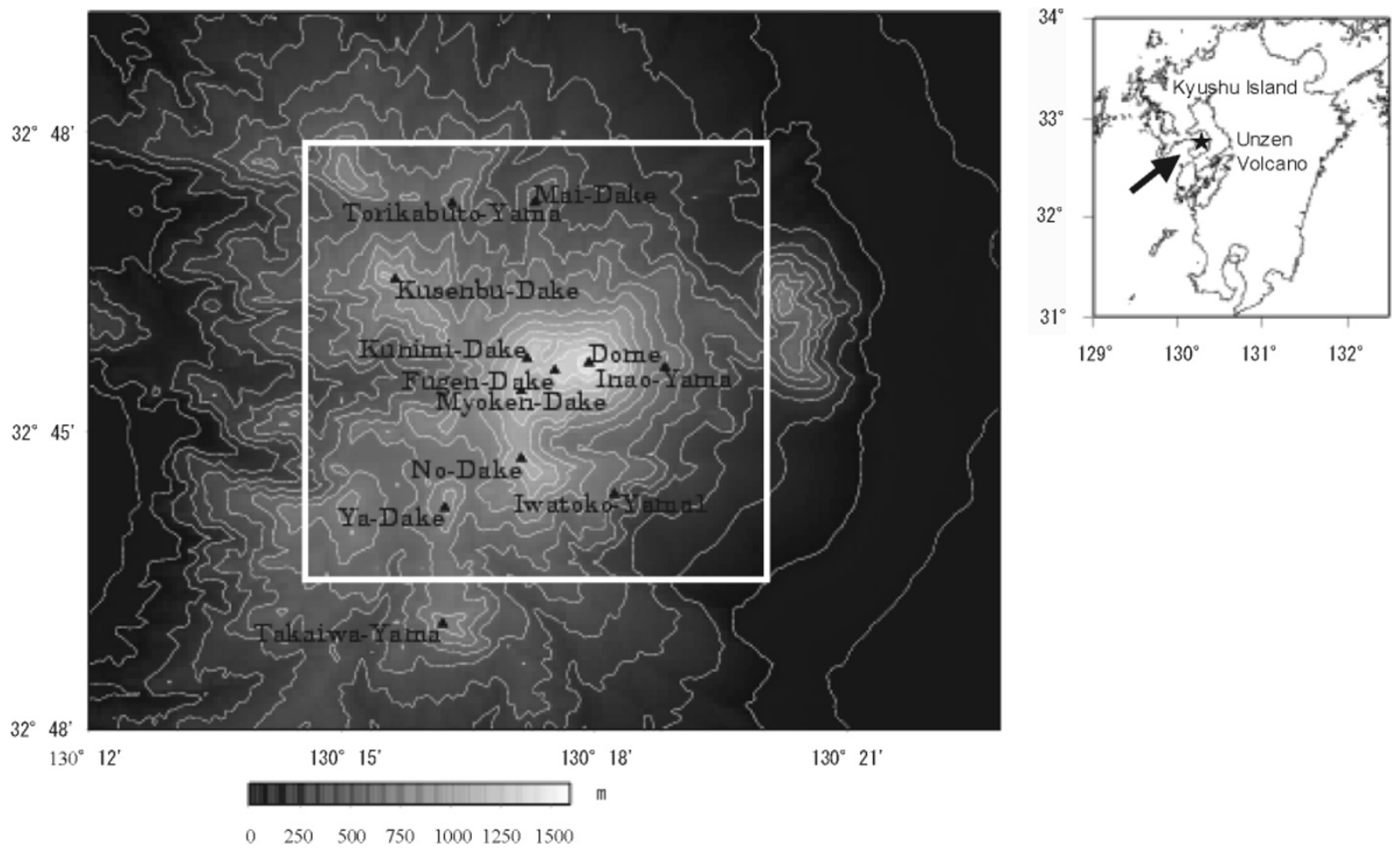

Fig. 1. Location and topography of Unzen volcano, Kyushu, Japan. Contour interval is $100 \mathrm{~m}$. The box shows the survey area in this study.

canoes (Figs. 2 and 3).

The Older Unzen Volcano is exposed mainly to the west of the Younger Unzen Volcano and underlies it in the eastern part, and is characterized mainly by effusion of thick lava flows. Debris-avalanche deposits and pyroclasticflow deposits of unknown source are sparsely exposed between lava domes and lava flows. The Unzen Onsen debris-avalanche deposit locally remains in and around a horseshoe-shaped collapsed scar west of Yadake.

Younger Unzen Volcano comprises Nodake, Myokendake, Fugendake and Mayuyama (outside of this survey area) volcanoes and is characterized mainly by the formations of lava domes and their collapsed pyroclastic deposit. Fugendake volcano is built within the horseshoe-shaped scar of Myokendake, and its eruption products spread over the flank of Myokendake. Nodake volcano is an isolated volcanic center adjacent to Myokendake. The stratigraphy of the eruption products was established mainly by locally exposed sparse key tephras and radiometric ages (Fig. 3).

\section{Survey Operation and Data Reduction}

The helicopter-borne aeromagnetic survey assisted by the Nagasaki Prefecture was carried out on September 18, 2002. Each of two survey flights covered the summit area of Unzen volcano. In order to obtain a detailed magnetization distribution of the Unzen volcano, it is neccessary to measure at a low altitude along the rugged topographic relief. However, there was no helicopter with enough impelling force to climb steep slope of this area. As a result, an innovative spiral flight path at a constant terrain clearance over the rugged topographic relief were adopted, instead of traditional straight line plan. Probably this is the first practice of spiral flight in surveying volcanos. We believe that this plan provides a more detailed distribution of the magnetic anomaly field.

In addition, we made 2 flights at different elevations in order to increases the amount of information. One is at an average altitude of $320 \mathrm{~m}\left(F_{\text {light }}\right)$ above the ground, the other is at $180 \mathrm{~m}\left(F_{\text {light }}\right)$, both with a line spacing of about $50 \mathrm{~m}$. The standard deviations from the average altitude are $64.6 \mathrm{~m}$ and $57.7 \mathrm{~m}$, respectively. Figs. 4(a) and 4(b) show both the flight-path locations and flight-altitudes above the ground in the two flights. The geomagnetic total field was recorded by an optical pumping magnetometer (GEOMETRICS) installed in a sensor bird and an Overhauser proton magnetometer (GEM) suspended by a cable of $10 \mathrm{~m}$ long under the airframe. The sampling intervals of these magnetometers are $0.1 \mathrm{sec}$ and $0.5 \mathrm{sec}$, respectively. However, we don't use the data recorded by the GEM magnetometer in this study, because the data tended to fluctuate. While real time navigation was achieved by a portable GPS receiver with a PC monitor, the GPS data of the sensor bird and the GPS data at the reference station in Nita-toge (both with 1-second sampling) were made to interfere in the precise positioning data of the bird, and it was analyzed by Precious Kinematics method with the PNAV software of Ashtech. The equipment utilized and the specifications in this survey are summarized in Table 1 and Fig. 5. In this study, we used the magnetic field data by the GEOMETRICS sensor and the data were resampled into $1.0 \mathrm{sec}$ intervals to coincide with the GPS data.

Diurnal magnetic variations of extra-terrestrial origin were removed by subtracting the total field data (Fig. 6) recorded at a reference station in Mayuyama dam site, 

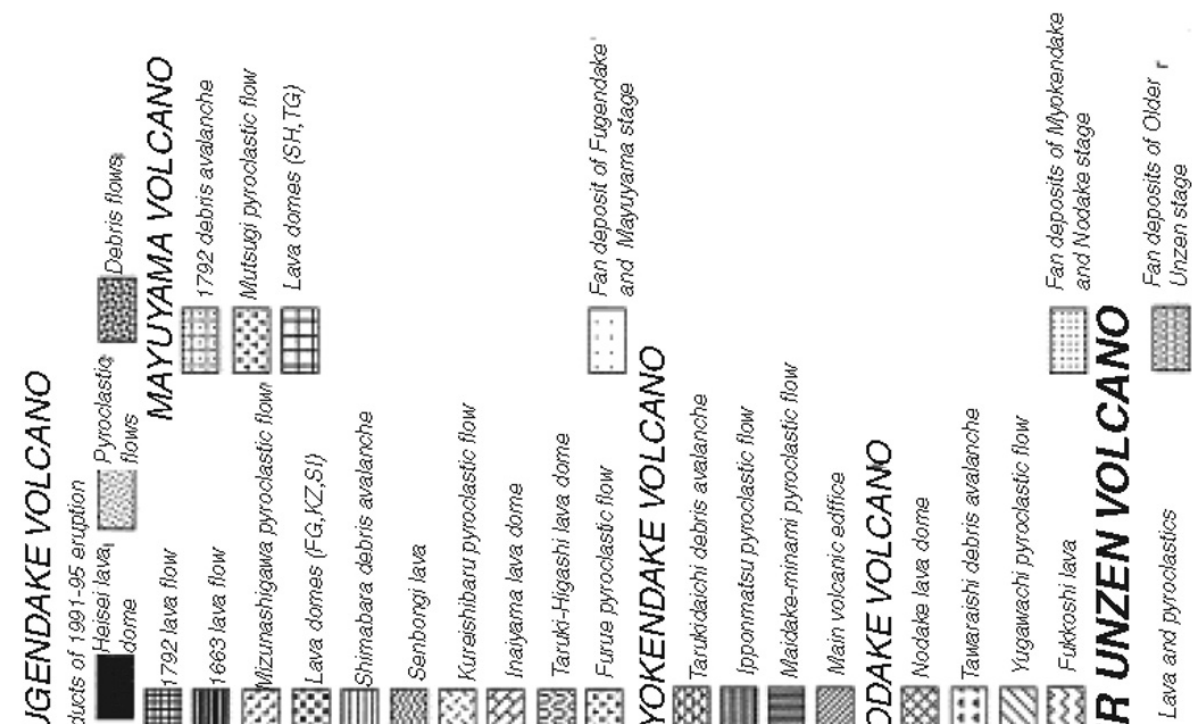

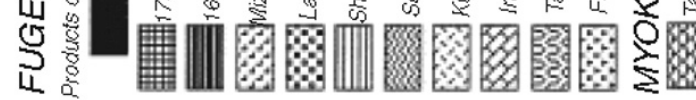
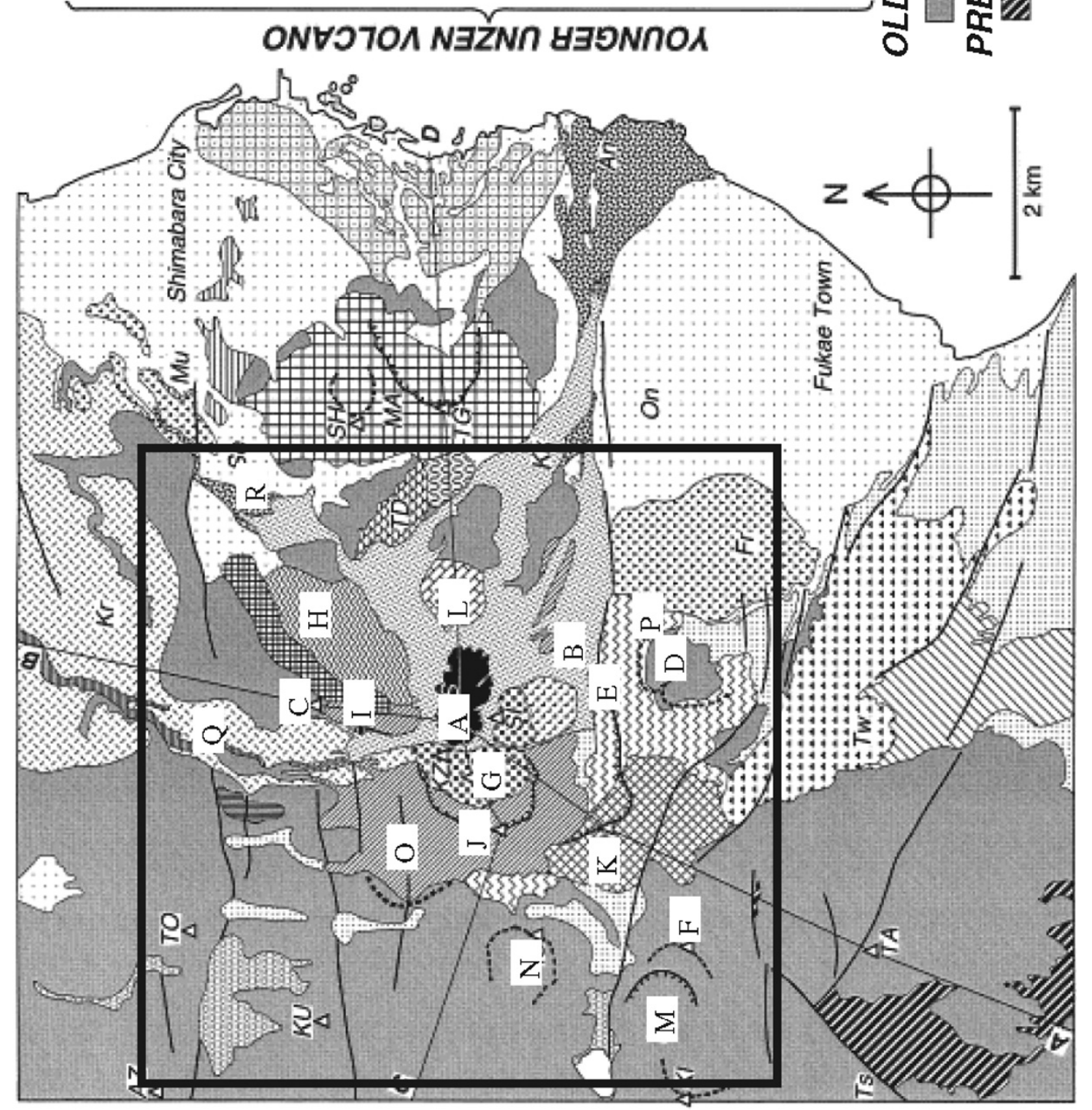

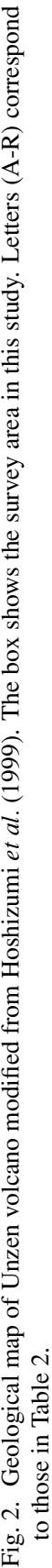




\section{Younger Unzen volcano}

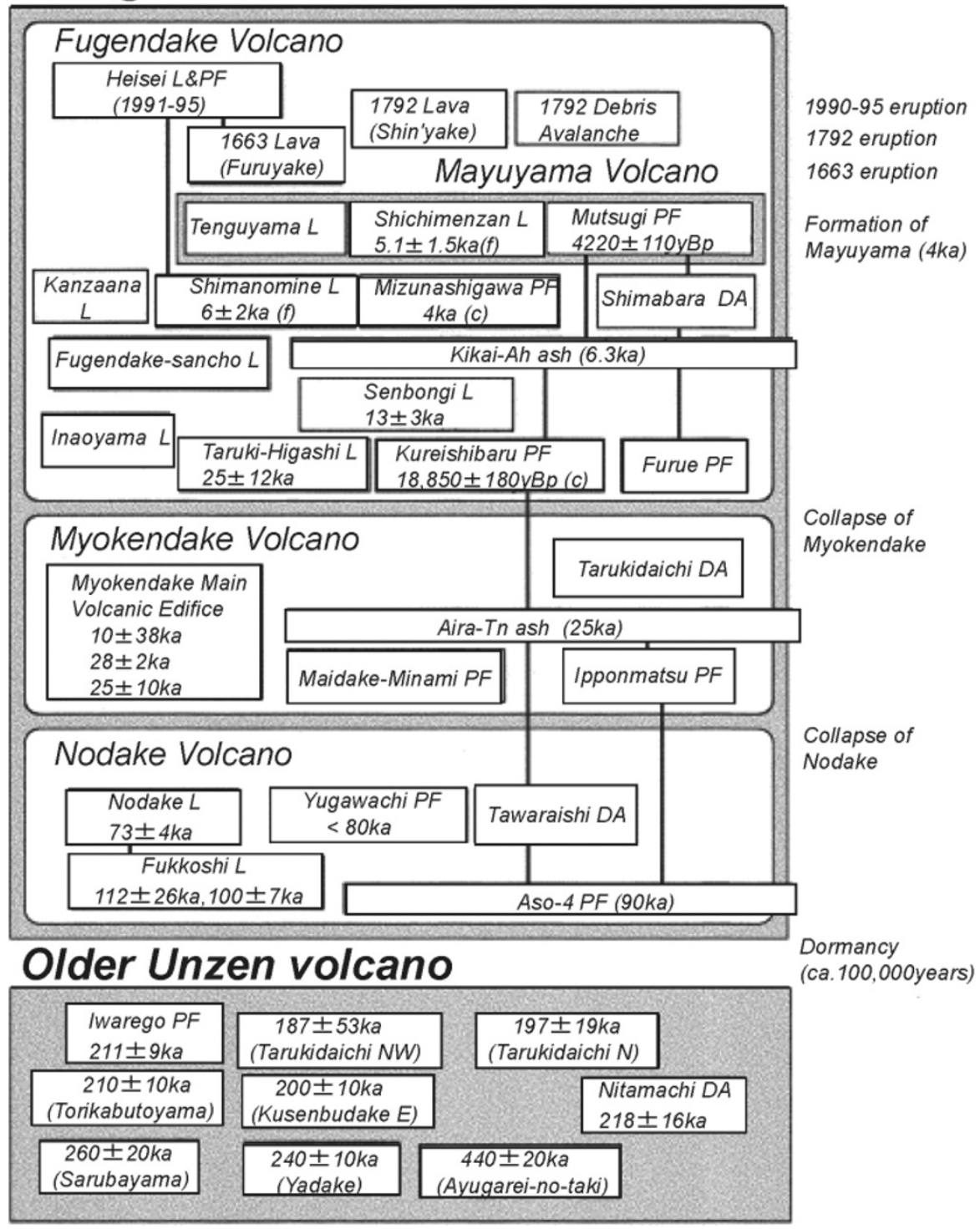

Fig. 3. Composite stratigraphic relations of geologic units of the Younger Unzen Volcano and Older Unzen Volcano, after Hoshizumi et al. (1999). $\mathrm{L}=$ lava; $\mathrm{PF}=$ pyroclastic flow deposit; $\mathrm{DA}=$ debris-avalanche deposit.

and the International Geomagnetic Reference Field (IGRF 2000) was subtracted from the data using the software of Nakatsuka (2003), in order to remove the regional trend of Earth's internal deep source.

\section{Data Analysis}

\subsection{Estimation of terrain magnetization}

After correction for diurnal magnetic variation and IGRF 2000 , the average terrain magnetization was estimated using both flight data in order to reduce the magnetic effect of topography to highlight lava flows whose magnetization departs from the average for the volcano, landslides and altered areas. To perform this estimation, the terrain altitude data in a $50 \mathrm{~m}$-grid were prepared for the area of $30 \mathrm{~km}$ by $30 \mathrm{~km}$ centered at the survey area. The terrain effect was synthesized by an assembly of small prismatic bodies (Fig. 7). The top depths coincide with the topographic surface and the bottom depths are assumed to be $500 \mathrm{~m}$ below sea level. Generally in this model, the anomalous magnetic field $g_{i}$ at an observation point $i$ is written as

$$
g_{i}=\sum_{j} \omega_{i j} \cdot J_{j}
$$

where $\omega_{i j}$ indicate the anomalous magnetic field at $i$-th observation point due to a prism with unit magnetization at $j$-th source position, and $J_{j}$ is the magnetization of $j$ th prism. The explicit form of $\omega_{i j}$ is obtained by Bhattacharyya (1964) and Nakatsuka (1981) as follws;

$$
\begin{gathered}
w_{i j}=-\left.\left.\left.[f(a, b, c)]\right|_{a=a_{1}} ^{a=a_{2}}\right|_{b=b_{1}} ^{b=b_{2}}\right|_{c=c_{1}} ^{c=c_{2}} \\
f=\frac{M n+m N}{2} \ln \frac{r-a}{r+a}+\frac{N l+n L}{2} \ln \frac{r-b}{r+b} \\
+\frac{L m+l M}{2} \ln \frac{r-c}{r+c}+L l \tan ^{-1} \frac{b c}{r a} \\
+M m \tan ^{-1} \frac{c a}{r b}+N n \tan ^{-1} \frac{a b}{r c} .
\end{gathered}
$$


(a)

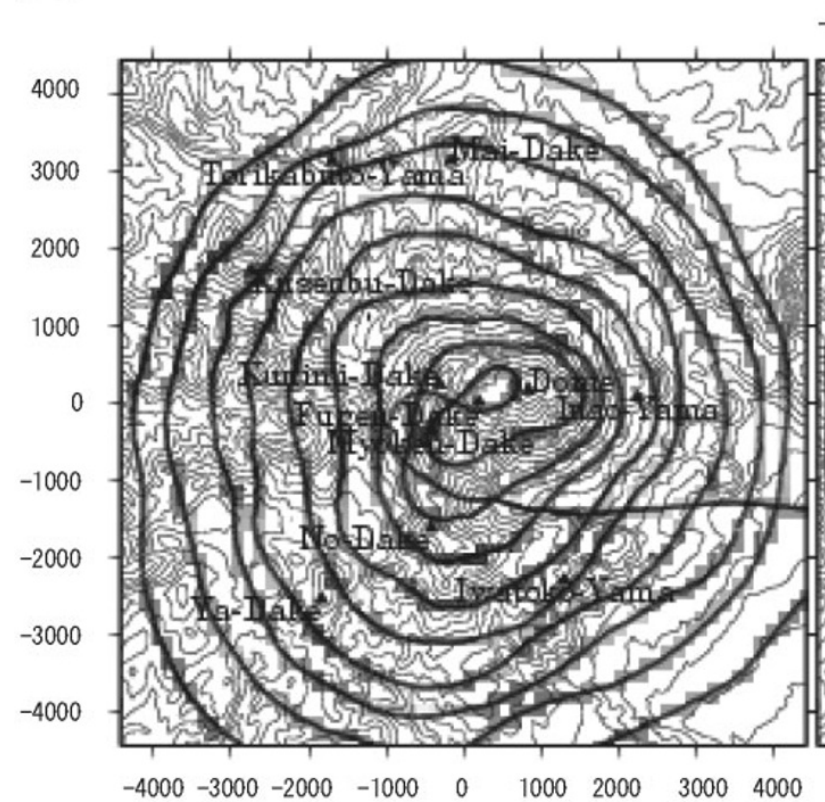

(b)

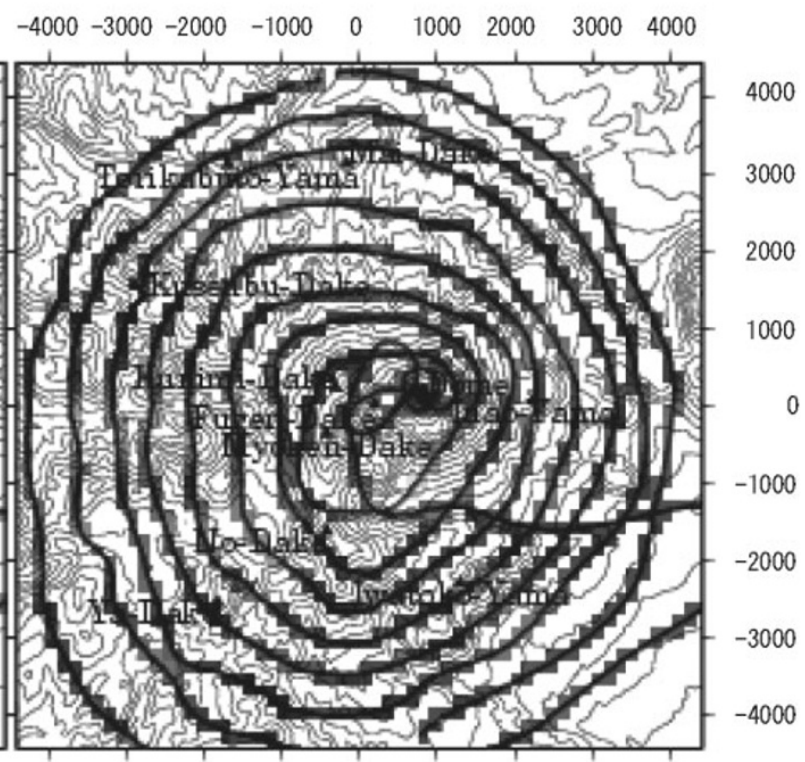

$50 \quad 100 \quad 150200 \quad 250 \quad 300 \quad 350 \quad 400 \quad 450$

Fig. 4. Trackline paths, for Flight (a) and Flight $_{L}$ (b). The observation altitudes above ground are represented in gray-scale along spiral paths. Topographic contour interval is $30 \mathrm{~m}$.

Table 1. Specifications and equipment utilized in this aeromagnetic survey.

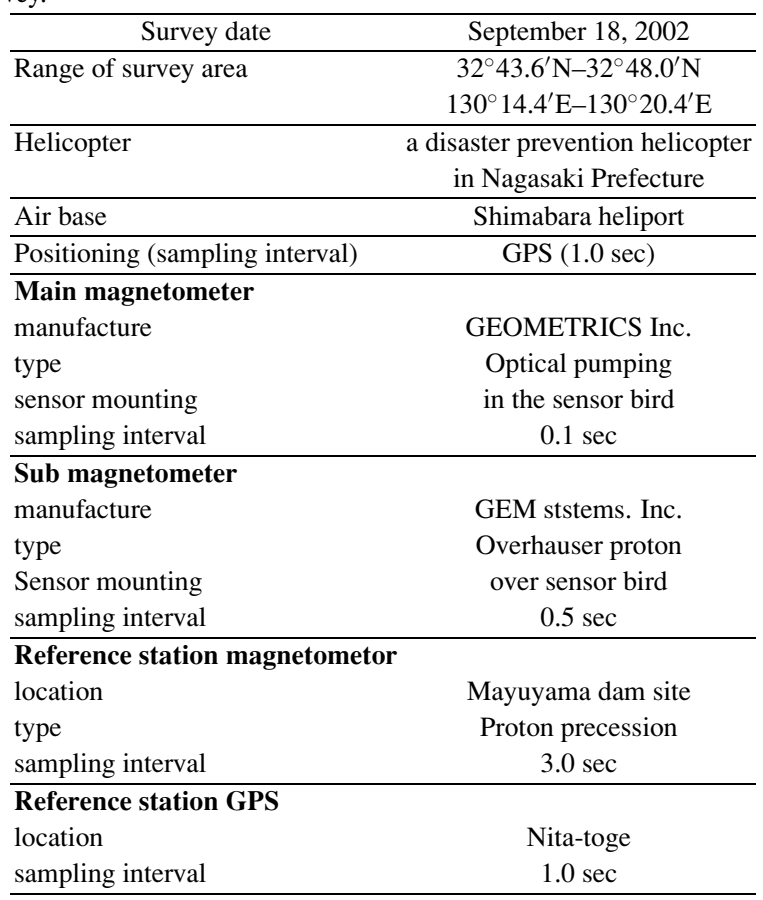

$$
\begin{aligned}
r= & \sqrt{a^{2}+b^{2}+c^{2}} & & \\
& a_{1}=x_{j}-(\Delta x / 2)-x_{i}, & & b_{1}=y_{j}-(\Delta y / 2)-y_{i}, \\
& c_{1}=z_{j}-z_{i}, & & a_{2}=x_{j}+(\Delta x / 2)-x_{i}, \\
& b_{2}=y_{j}+(\Delta y / 2)-y_{i}, & & c_{2}=z_{j}+\Delta z-z_{i},
\end{aligned}
$$

where $\left(x_{i}, y_{i}, z_{i}\right)$ indicates the $i$-th observation point, $\left(x_{j}, y_{j}, z_{j}\right)$ is the $j$-th source point and $(\Delta x, \Delta y, \Delta z)$ is the

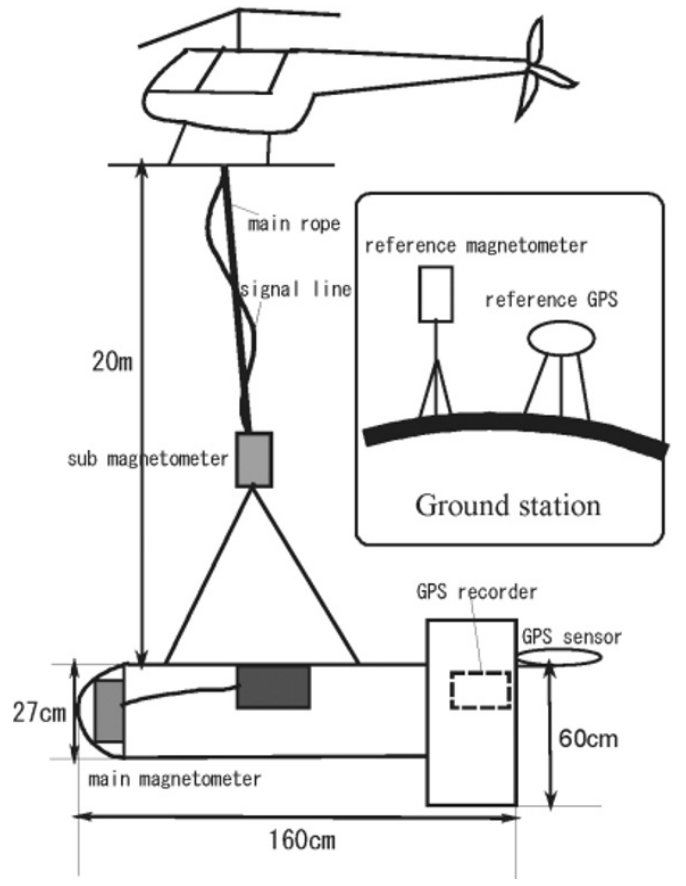

Fig. 5. Equipment utilized in the aeromagnetic survey.

dimension of the prism. The notation $\left.[f(x)]\right|_{x=x_{1}} ^{x=x_{2}}$ indicates the calculation $f\left(x_{2}\right)-f\left(x_{1}\right)$. Here, $(L, M, N)$ and $(l, m, n)$ are the direction cosines of the normal field and magnetization vector, respectively.

In the terrain effect estimation, the magnetization inten- 


\section{Diurnal variation of geomagnetic total force}

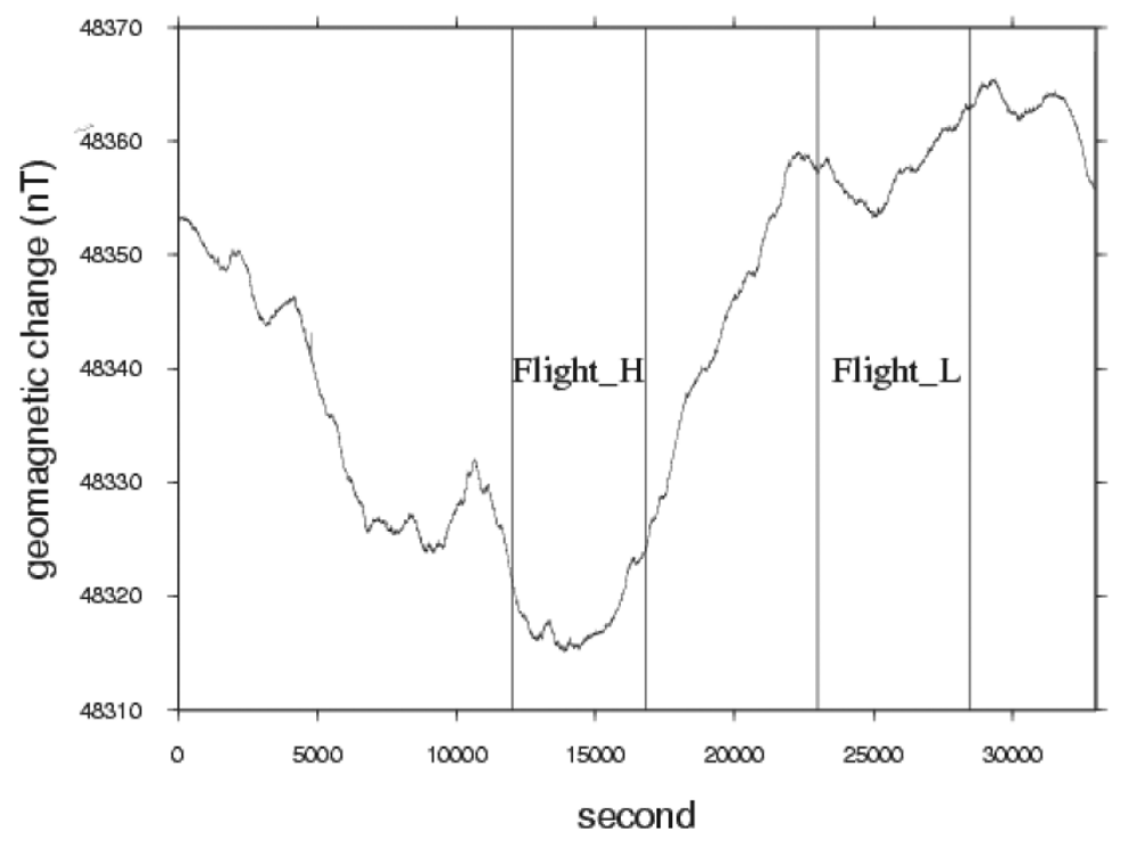

Fig. 6. Diurnal variation of geomagnetic total force observed at Mayuyama dam site on the survey date.

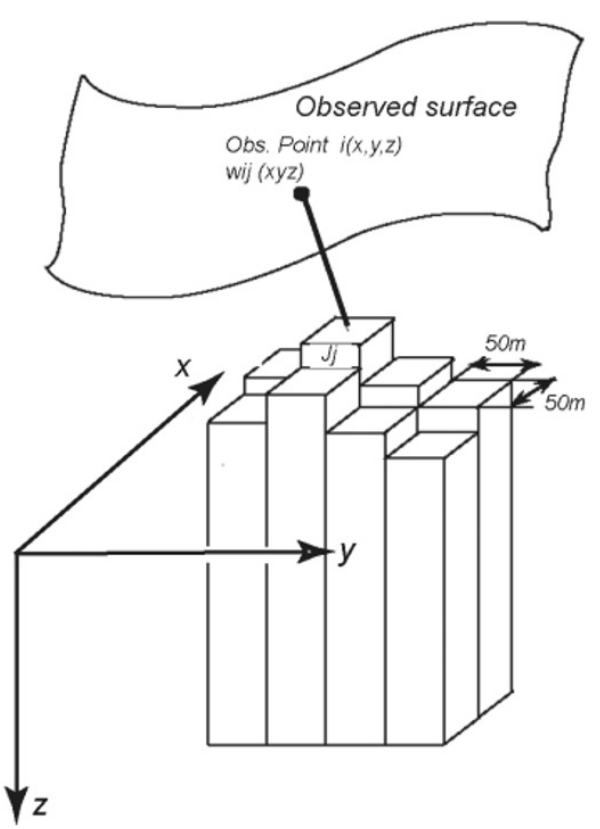

Fig. 7. Schematic configuration of the terrain model used to calculate the average terrain magnetization and to estimate magnetization intensity distribution. $J_{j}$ : Magnetization of a prism at $j$-th point, $w_{i j}$ : the geometric contribution factor of a prism at $j$-th point to the magnetic anomaly at the observation point $\left(x_{i}, y_{i}, z_{i}\right)$.

sity was assumed to be a constant ( $J_{j}=$ const.), and each prism is considered to be magnetized with a $46.5^{\circ}$ inclination and $6^{\circ} \mathrm{W}$ declination, identical to the direction of the Earth's present magnetic field.

Then, the averaged magnetization of the survey area was derived to be $3.1 \mathrm{~A} / \mathrm{m}$, using a statistical correlation method adopted by Grauch (1987),

$$
\bar{J}=\frac{\sum_{i}\left(f_{i}-\bar{f}\right) \cdot\left(g_{i}-\bar{g}\right)}{\sum_{i}\left(g_{i}-\bar{g}\right)^{2}}
$$

where $f_{i}$ is the observed anomaly, and $g_{i}$ is the calculated terrain effect of unit magnetization $\left(J_{j} \equiv 1\right)$, both for the observation point $i$, and $\bar{f}$ and $\bar{g}$ are the average values. Then, the effect of uniform magnetization of $3.1 \mathrm{~A} / \mathrm{m}$ was subtracted from each magnetic anomaly value.

Besides expected local differences in magnetization, however, there still remain a large number of magnetic anomalies with relatively short wavelengths, probably due to the observation error especially in position fix and the inaqcuracy of terrain model. Actually, for example, the distances between adjacent position fixes are irregular, though they are expected to be more smooth. Therefore, in order to reduce such large distortions and noise, we applied an upward continuation filtering to the terrain-corrected anomalies, using the equivalent anomaly technique described next. 4.2 Upward continuation of geomagnetic anomalies using the equivalent anomaly nethod

We consider the continuation of the surface distribution of magnetic anomalies, on a regular grid. Using a procedure developed by Makino et al. (1993), magnetic anomalies on an irregular surface can be reduced to equivalent anomalies on a source surface, which yield the base from which calculate the magnetic anomaly distribution on another surface above the sources.

We used this scheme to obtain upward continued anomalies on a surface parallel to the topographic relief of this 
(a)

(b)

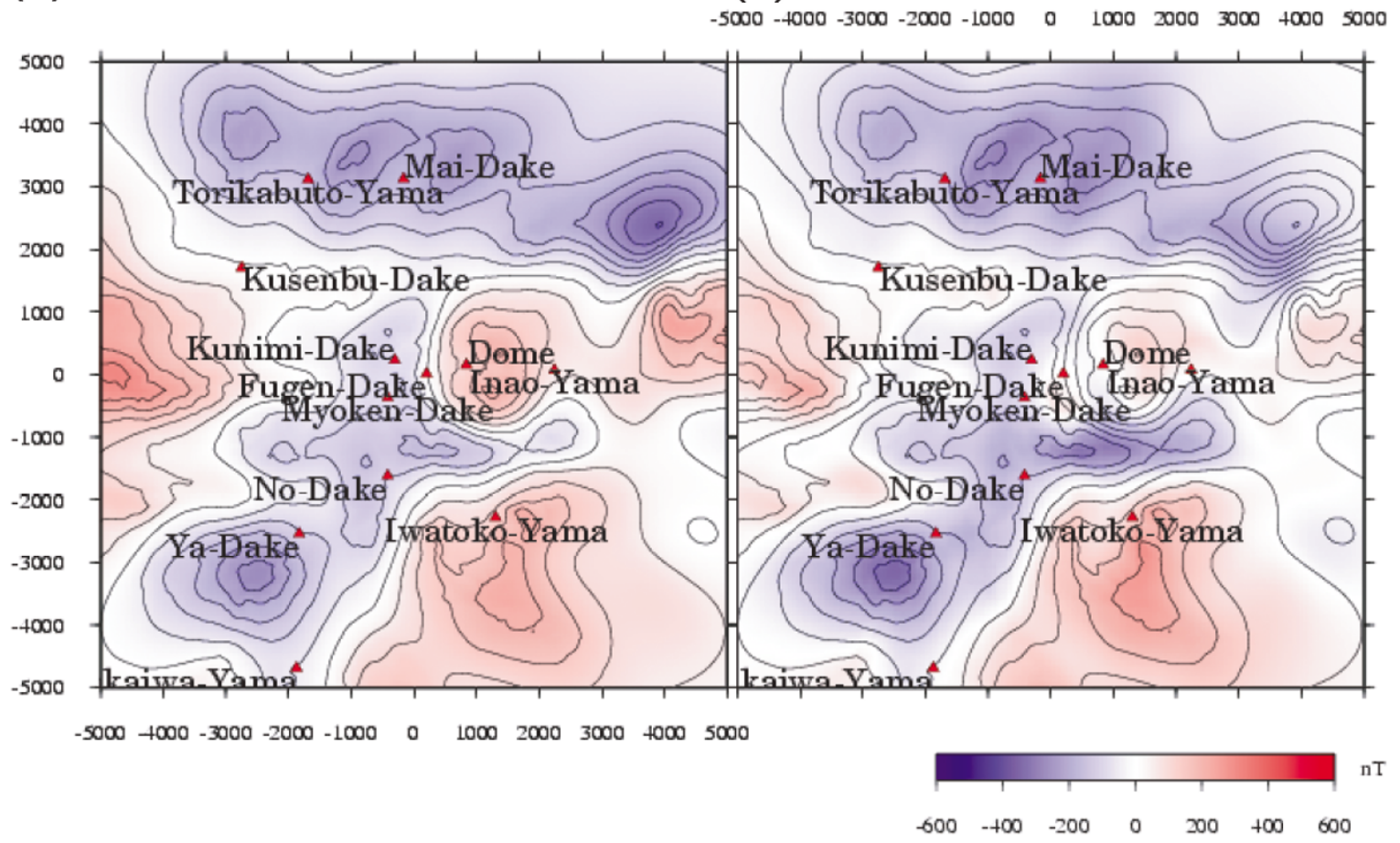

Fig. 8. Upward continued magnetic anomalies to the surface $500 \mathrm{~m}$ higher than the average altitude of the actual observations for $F$ light $t_{H}$ (a) and Flight $_{L}(\mathrm{~b})$. The contour intervals are $50 \mathrm{nT}$.

survey area. This method extracts harmonic components and provides upward continued values, along with reducing the noise included in the observations. Figs. 8(a) and 8(b) show the upward continued anomalies used as input in the magnetization intensity mapping discussed in the next section. In this study, the equivalent anomalies are the results of the asymptotic solution of the conjugate gradient (CG) method when the iteration was terminated at 20th trial. Here, the surfaces of equivalent anomalies were assumed $600 \mathrm{~m}$ below the observation surfaces, and a wider area 1.8 $\mathrm{km}$ beyond the survey area was taken into account in order to avoid edge effects. The reduction surfaces parallel to the ground, to which magnetic anomalies were attributed, were selected so that the average altitude of the surfaces are 500 $m$ higher than the actual observation.

Here, there are two reasons why we did not calculate single equivalent anomaly distribution for both data sets (320 $\mathrm{m}$ and $180 \mathrm{~m}$ above the ground). First, we wanted to check how accurately each position is decided by comparing both magnetic anomaly patterns. The other is for the stabilization of asymptotic solution.

\subsection{Magnetization intensity mapping}

In order to obtain new more detailed information than the previous aeromagnetic studies about the subsurface structure, such as lava flows, pyroclastic flows, landslide deposits and hydrothermally altered areas, we carried out a magnetization intensity mapping on the assumption that the magnetic anomalies are caused by the terrain magnetized in the same direction as the present Earth's magnetic field, a reasonable assumption given the young $(<300,000)$ age of Unzen, and the magnetization intensity varies only laterally (Okuma, 1994, 1998; Nakatsuka, 1995).
Now we consider the magnetic anomalies caused by an assembly of prismatic bodies (Fig. 7) as before. The total anomaly, $g_{i}$, for all prismatic bodies can be written again by

$$
g_{i}=\sum_{j=1}^{m} w_{i j} \cdot J_{j}(i=1,2, \ldots, n) .
$$

Here, $n$ and $m$ denote the number of observation points and the number of source prisms, respectively. The magnetization $J_{j}$ of each prism is not a constant but variable this time. So, the magnetization $J_{j}$ of each prism can be obtained from the solution of $n$ simultaneous linear equations,

$$
\sum_{j=1}^{m} w_{i j} \cdot J_{j}=f_{i}(i=1,2, \ldots, n) .
$$

In this study, as we deal with the case of $m<n$. Equation (4) has no exact solution, and usually a least-squares method is used to estimate $J_{j}(j=1,2, \ldots, m)$. Here we employed the CG method (Nakatsuka, 1995; Okuma, 1998) instead of solving Eq. (4) directly. The CG method also gives a least-squares solution.

We applied this magnetization intensity mapping method to the anomalies of Figs. 8(a) and 8(b) employing the CG method with the following configuration of assumed prismatic bodies:

1) We divided the crust into square mesh of $150 \mathrm{~m}$ in horizontal extent, and the vertical extent from surface to 500 $\mathrm{m}$ below sea level was considered. The top face undulation represented by $50 \mathrm{~m}$-grid topography was taken into account.

2) The prismatic bodies are arranged to cover an area 


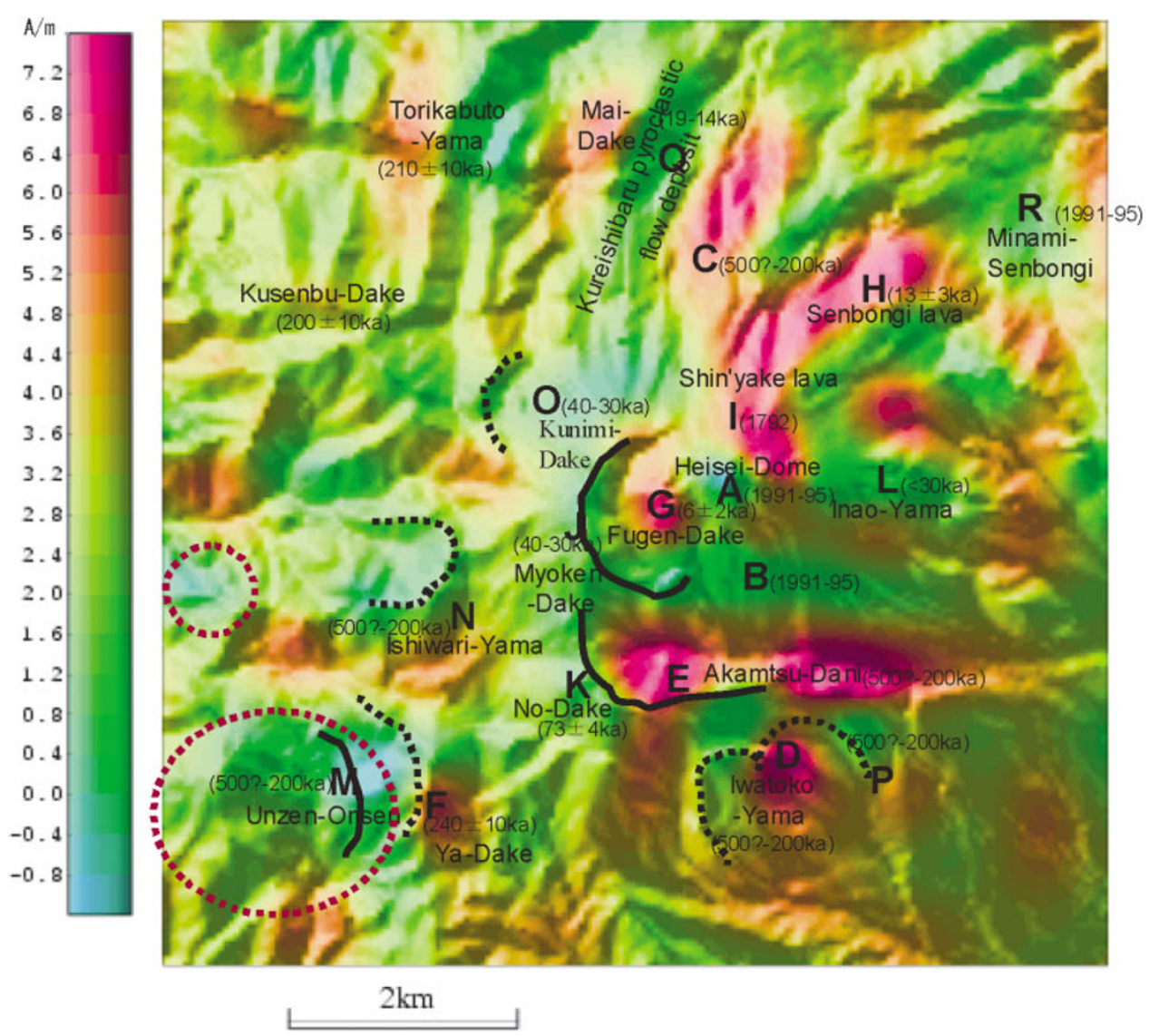

Fig. 9. Result of the magnetization intensity mapping with a topographic shading drawn using the software of Nakatsuka (2003) . The magnetic anomalies of Figs. 8(a) and 8(b) were the input data for the inversion process. Assumed sources were distributed in wider area of $12 \mathrm{~km} \times 12 \mathrm{~km}$, but the results are shown only for $8.4 \mathrm{~km} \times 8.4 \mathrm{~km}$, within the range of the input data. Letters (A-R) correspond to those in table 2 . Block solid lines indicate confirmed collapsed walls, and probable or possible ones are shown as broken lines after Watanabe and Hoshizumi (1995), while the broken red lines indicate the alteration zone. The age was also described according to Fig. 3.

$1.8 \mathrm{~km}$ beyond the survey area in order to avoid edge effects.

In this study we used $n=6498$ for the two sets data (Figs. 8(a) and (b)) of 57 by 57 grids which corresponds to the area of $8.4 \mathrm{~km}$ by $8.4 \mathrm{~km}$, and prepared $m=6400$ for the unknown parameter of 80 by 80 grids in the area of $12.0 \mathrm{~km}$ by $12.0 \mathrm{~km}$. Here, both of $n$ and $m$ have same grid width of $150 \mathrm{~m}$ by $150 \mathrm{~m}$. The inversion was carried out using both Flight $_{H}$ and Flight $L$ data, simultaneously. Fig. 9 shows the result of the inversion. The iterations were stopped after 20 trials when the standard deviations of differences between the observed and calculated fields were $29.9 \mathrm{nT}$ and 34.7 nT for $F l i g h t_{H}$ and $F$ light $_{L}$, respectively. Therefore, these cut-offs were not chosen. The residual anomalies for Flight $_{H}$ and Flight $L$ are shown in Fig. 10. There is a portion with large residual from the result of Fig. 10 around the Kunimi-Dake. Probably this is considered because either the position accuracy was not good. However, it turns out that the calculated anomalies have explained the observed ones mostly generally. In addition, it does not know how exact the obtained magnetization intensity is because of lack of rock magnetism information.

\section{Results and Discussion}

First, the averaged magnetization of the survey area was estimated to be $3.1 \mathrm{~A} / \mathrm{m}$ in our survey area. Please note that in the surveyed area there is no previous estimation of the apparent magnetic susceptibility of rocks. As for the similar estimation of average magnetization, Nakatsuka (1994) obtained a value of $2.9 \mathrm{~A} / \mathrm{m}$ for a relatively large region of $23 \mathrm{~km}$ by $33 \mathrm{~km}$, and Mogi et al. (1995) gave $5.1 \mathrm{~A} / \mathrm{m}$ for a smaller area of $5.5 \mathrm{~km}$ by $8 \mathrm{~km}$. The result of Mogi et al. (1995) is affected by the presence of the highly magnetized Mayuyama rocks and the absence of the low-magnetized Heisei lava. Therefore, in this study, the average value of magnetization is more reliable for the summit area of Unzen volcano, compared with the results of previous aeromagnetic analysis. As Unzen volcano is mainly composed of lavas and pyroclastic products of andesite, we believe that this value is correctly estimated.

Next, we discuss some characteristics of the distribution of the magnetization intensity, as shown in Fig. 9, and its relation to the geology of Unzen Volcano. Table 2 summarizes characteristic maxima and minima revealed in the map of magnetization intensity and corresponding geologic features. However, it is only a discussion on a lateral distribution, since no information on the depth or magnetization direction is derived from this mapping.

(1) On Heisei-Shinzan (Dome), a magnetization low of $<0.5$ A/m (A: 1991-95) is locally distributed. This suggests that the Heisei lava produced by the 1990-1995 eruption has not yet been cooled beneath its Curie temperature. 
(a)

(b)

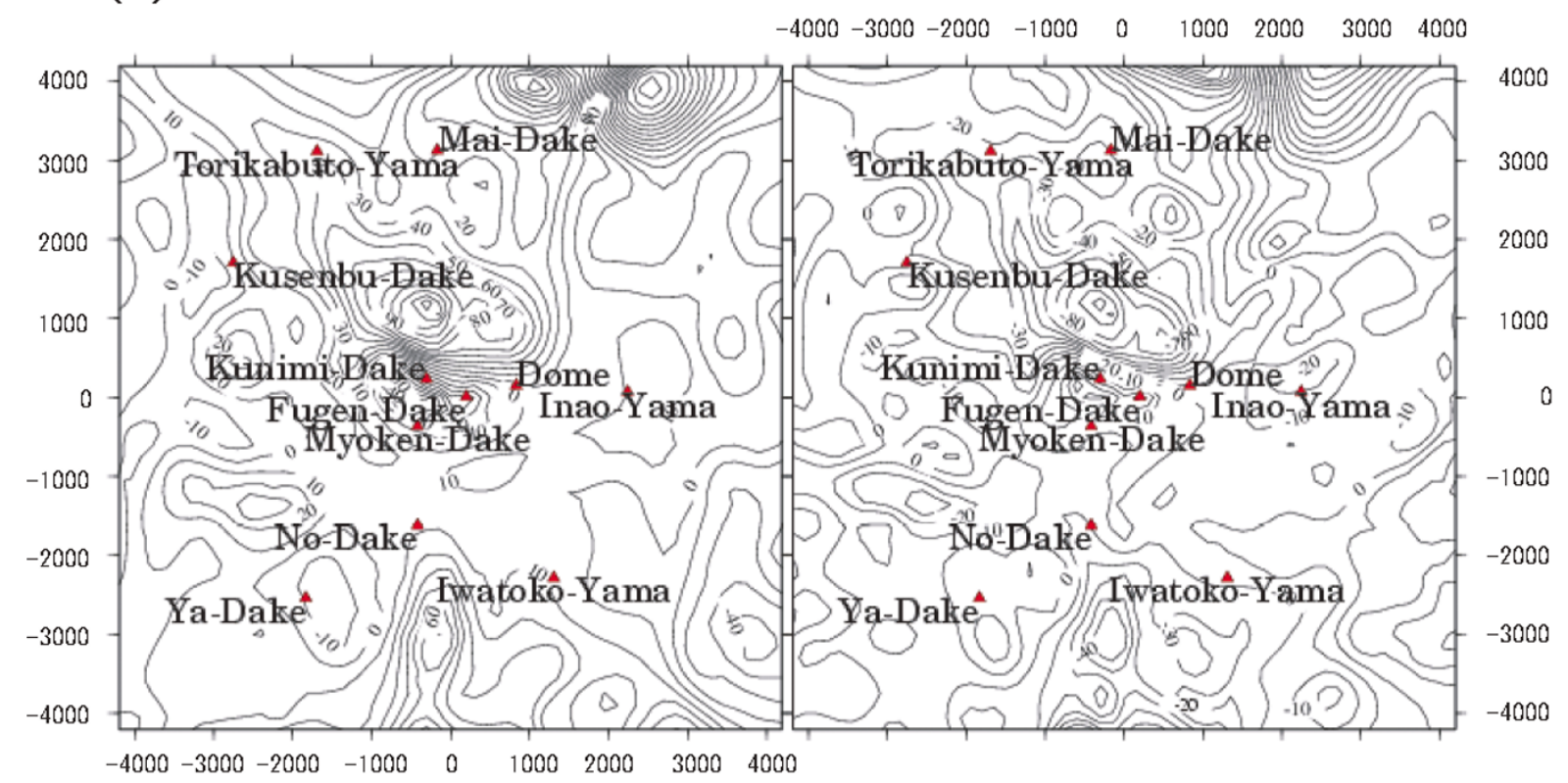

Fig. 10. Misfit of the magnetization intensity inversion, residual anomalies obtained by substracting the calculated anomalies (determined from Fig. 9) from the observed ones (Figs. 8(a) and 8(b)). The standard deviations of residual anomalies were $29.9 \mathrm{nT}$ and $34.7 \mathrm{nT}$ for Flight $H$ and Flight $_{L}$, respectively.

In addition, magnetization lows of $<0.5 \mathrm{~A} / \mathrm{m}$ predominate in an area south of the Dome (B: 1991-95). This region corresponds to block-and-ash flows and talus deposits from 1991-95 activity. Although both the young flow and the old one consist of dacite block, lapilli and ash, the magnetization intensity of the young flow is smaller than the old one (mostly $>3 \mathrm{~A} / \mathrm{m}$ ).

(2) Magnetization highs of 4.0 to $7.5 \mathrm{~A} / \mathrm{m}$ are distributed in $2 \mathrm{~km}$ north of Dome (C: 500?-200 ka), near the summit of Iwatoko-Yama (D: 500?-200 ka), on the south slope of EW trending Akamatsu-Dani valley (E: 500?-200 ka), and at Ya-Dake (F: 230-250 ka). These areas of magnetization highs correspond to lava flows of the Older Unzen volcano. However, magnetization highs predominate over lava flows of the Younger Unzen volcano. Magnetization highs of 5 to $6.5 \mathrm{~A} / \mathrm{m}$ predominate around Fugendake (G: 8-4 ka), which correspond to dacite lavas of Fugendake. The area of magnetization highs $(7.5 \mathrm{~A} / \mathrm{m})$ predominate around $2 \mathrm{~km}$ northeast of Dome (H: 16-10 ka), which correspond to the Senbongi lava. A magnetization high $(7.5 \mathrm{~A} / \mathrm{m})$ approximately $1 \mathrm{~km}$ north of Dome (I: 1792), corresponds to the Shin'yake lava of 1792. Although the upper part of Shin'yake lava has high magnetization, the down-stream part of Shin'yake lava has lower magnetization. It is because Shin'yake lava differed from the conventional eruption style and cooling of rock was rapid (Ohta, 1984). So it is thought that the lava flow cooled quickly and gained high magnetization in the upper part, and low magnetization of block-and-ash flow deposits accumulated in a down-stream part.

In contrast, magnetization lows predominate over other lavas of Unzen volcano. Magnetization lows of $1.5 \mathrm{~A} / \mathrm{m}$ extend from the Myoken-Dake lava (J: 20-30 ka) to the NoDake lava (K: 77-69 ka). The results of the aeromagnetic survey by Mogi et al. (1995) also showed that the magne- tization intensity of both Myoken-Dake and No-Dake lavas are lower than Fugen-Dake lava. In addition, magnetization lows of $1.0 \mathrm{~A} / \mathrm{m}$ predominate around Inao-Yama (L: $<30 \mathrm{ka}$ ), a parasitic dome on the eastern flank of Fugendake. Nakatsuka (1994) also showed similar results using high-altitude aeromagnetic data.

Ozima et al. (1992) found that rocks with similar bulk chemical composition from different eruptions possessed considerably different magnetization values, and pointed out that the magnetic properties are sensitive to the ferric/ferrous ratio in the chemical compositions of the magnetic minerals and thermal history, which reflects different oxygen fugacity during the cooling of the rocks. This may be one reason for the variations of magnetization values. Compositional variations in lavas can also explain magnetization variations.

(3) As shown in Fig. 9, magnetization lows locally predominate in this mapped area. The origins of the magnetization lows are suggested as follows.

(i) Magnetization lows of $<0.5 \mathrm{~A} / \mathrm{m}$, which exist around Unzen hot spring (M: 500?-200 ka), Ishiwari-Yama (N: 500?-200 ka), northwest of Kunimi-Dake (O: 40-30 ka) and the area surrounding Iwatoko-Yama (P: 500?-200 ka), are associated with the collapsed walls generated by the volcano activity. It is thought that these rock bodies with remanent magnetization were fractured into pieces and then rotated into random directions by landslides (cf. Finn et al., 2001).

(ii) The magnetization low around Unzen hot spring (M: 500 ?-200 ka) is correlated not only to the collapsed wall but also to the hydrothermal alteration that destroyed the original magnetization. Therefore, another possible explanation for the low magnetization is the loss of magnetic minerals in rocks due to hydrothermal activity. 
Table 2. Characteristics of the distribution of magnetization intensity on Unzen Volcano. $(\mathrm{H})$ and $(\mathrm{L})$ in remarks denote magnetization highs and lows, respectively. Letters in the first column correspond to those in Fig. 9.

\begin{tabular}{|c|c|c|c|}
\hline $\begin{array}{c}\text { Symbol } \\
\text { (Remarks) }\end{array}$ & Locality & $\begin{array}{l}\text { Magnetization } \\
\text { Intensity }(\mathrm{A} / \mathrm{m})\end{array}$ & $\begin{array}{l}\text { Geologic features } \\
\text { (Age) }\end{array}$ \\
\hline $\mathrm{A}(\mathrm{L})$ & Heisei-Shinzan (Dome) & $<0.5$ & Heisei Lava (1991-95) \\
\hline $\mathrm{B}(\mathrm{L})$ & EW area south of the Dome & $<0.5$ & $\begin{array}{l}\text { Block-and-ash flow deposits } \\
\qquad(1991-95)\end{array}$ \\
\hline $\mathrm{C}(\mathrm{H})$ & $2 \mathrm{~km}$ north of Dome & 7.0 & $\begin{array}{c}\text { Lava flows of Older } \\
\text { Unzen Volcano }(500 ?-200 \mathrm{ka})\end{array}$ \\
\hline $\mathrm{D}(\mathrm{H})$ & Iwatoko-Yama & 6.5 & $\begin{array}{c}\text { Lava flows of Older } \\
\text { Unzen Volcano }(500 ?-200 \mathrm{ka})\end{array}$ \\
\hline $\mathrm{E}(\mathrm{H})$ & Akamatsu-Dani & 7.5 & $\begin{array}{c}\text { Lava flows of Older } \\
\text { Unzen Volcano }(500 ?-200 \mathrm{ka})\end{array}$ \\
\hline $\mathrm{F}(\mathrm{H})$ & Ya-Dake & 4.0 & $\begin{array}{c}\text { Lava flows of Older } \\
\text { Unzen Volcano }(250-230 \mathrm{ka})\end{array}$ \\
\hline $\mathrm{G}(\mathrm{H})$ & Fugen-Dake & 6.5 & $\begin{array}{c}\text { Fugendake, Kazaana and } \\
\text { Shimanomine Lavas ( } 8-4 \mathrm{ka})\end{array}$ \\
\hline $\mathrm{H}(\mathrm{H})$ & $2 \mathrm{~km}$ northeast of Dome & 7.5 & Senbongi Lava (16-10 ka) \\
\hline $\mathrm{I}(\mathrm{H})$ & $1 \mathrm{~km}$ north of Dome & 7.5 & Shin'yake Lava (1792) \\
\hline $\mathrm{J}(\mathrm{L})$ & Myoken-Dake & 1.5 & Myokendake Lava (30-40 ka) \\
\hline $\mathrm{K}(\mathrm{L})$ & No-Dake & 1.5 & Nodake lava (77-69 ka) \\
\hline $\mathrm{L}(\mathrm{L})$ & around Inao-Yama & 1.0 & Inaoyama Lava (<30 ka) \\
\hline $\mathrm{M}(\mathrm{L})$ & around Unzen-Onsen & $<0.5$ & $\begin{array}{l}\text { Hot spring and around } \\
\text { collapsed wall }(500 ?-200 \mathrm{ka})\end{array}$ \\
\hline $\mathrm{N}(\mathrm{L})$ & around Ishiwari-Yama & $<0.5$ & $\begin{array}{l}\text { around collapsed wall } \\
(500 ?-200 \mathrm{ka})\end{array}$ \\
\hline $\mathrm{O}(\mathrm{L})$ & northwest of Kunimi-Dake & $<0.5$ & around collapsed wall \\
\hline $\mathrm{P}(\mathrm{L})$ & the area surrounding Iwatoko-Yama & $<0.5$ & $\begin{array}{l}\text { Myokendake Lava (40-30 ka) } \\
\text { around collapsed wall } \\
(500 ?-200 \mathrm{ka})\end{array}$ \\
\hline $\mathrm{Q}(\mathrm{L})$ & east of Mai-Dake & $<0.5$ & $\begin{array}{c}\text { Kureishibaru pyroclastic } \\
\text { flow deposit, vally (19-14 ka) }\end{array}$ \\
\hline $\mathrm{R}(\mathrm{L})$ & around Minami-Senbongi & $<0.5$ & $\begin{array}{l}\text { block-and-ash flow deposit, } \\
\text { alluvial fan (1991-95) }\end{array}$ \\
\hline
\end{tabular}

(iii) The lowermost values of magnetization $<0.0 \mathrm{~A} / \mathrm{m}$ (Q: 19-14 ka), which occur in the valley, correspond to the Kureishibaru pyroclastic flow deposit, suggesting that this deposit is the cause of the magnetization low. Magnetization lows of $<0.5 \mathrm{~A} / \mathrm{m}$ also predominate around MinamiSenbongi (R: 1991-1995), which is an alluvial fan. In the Unzen Scientific Drilling Project (USDP) a borehole was dug on the northeastern flank of Minami-Senbongi, and it revealed that the subsurface contains block-andash flow deposits and lahar and debris avalanche deposits (Hoshizumi et al., 2002). It is thought that these types of rocks of the subsurface around Minami-Senbongi would have low magnetizations, which is consistent with our interpretations.

Finally, our results obtained from the aeromagnetic survey with spiral trajectories are consistent with past aeromagnetic analyses and gave further detailed and new information with a good correlation to the surface geology for understanding the history and eruption mechanism of the Unzen volcano.

\section{Conclusions}

We conducted an aeromagnetic survey at two different flight altitudes over Unzen Volcano using spiral trajectories with constant terrain clearances. From the total intensity data of optical pumping magnetometer, precise magnetic anomalies were derived for each observation surface by removing the effects of diurnal magnetic variations and the regional trend of IGRF 2000.

The statistical average of the terrain magnetization of Unzen volcano was estimated to be $3.1 \mathrm{~A} / \mathrm{m}$.

The aeromagnetic anomaly distributions on the two surfaces with different elevations are upward continued using an equivalent anomaly method to reduce the noise included in the observation. Then both data were used in a joint inversion to estimate the magnetization intensity distribution of Unzen volcano.

The resultant magnetization intensity map shows a good correlation with the results of past aeromagnetic analyses and with the surface geology features, in general. Furthermore, the more detailed and new geology information for understanding the history and eruption mechanism of the Unzen volcano was acquired. Lavas of Unzen volcano possess different magnetization values for each eruption event. In addition, magnetization lows correspond to areas such as collapsed walls, hydrothermal alteration zones, valley deposits and fan deposits, suggesting randomly oriented remanent magnetizations or a loss of magnetic minerals due to hydrothermal activity. The Heisei-Shinzan lava dome formed during the 1991-1995 eruption shows low mag- 
netization intensity values. This lower intensity indicates that lava dome on Heisei-Shinzan as a whole has not been cooled yet enough to acquire thermal remanent magnetization.

Acknowledgments. We are grateful to N. Oshiman, S. Okuma, R. Kubota, R. Yoshimura, and K. Yamazaki for useful discussions and helpful criticism. We also would like to express our appreciation to James Mori for his help to improve the quality of the manuscript. We are also thankfull to T. Nakatsuka and C. Finn for reviewing our paper and giving us valuable comments.

\section{References}

Bhattacharyya, B. K., Magnetic anomalies due to prism-shaped bodies with arbitrary polarization, Geophysics., 29, 517-531, 1964.

Finn, A. C. and L. A. Morgan, High-Resolution aeromagnetic mapping of volcanic terrain, Yellowstone National Park, J. Volcanol. Geotherm. Res., 115, 207-231, 2002.

Finn, A. C., T. Sisson, and M. Deszcz-Pan., Aerogeophysical measurements of collapse-prone hydrothermally altered zones at Mount Rainier volcano, Nature, 409, 600-603, 2001.

Grauch, V. J. S., A new variable-magnetization terrain correction method for aeromagnetic data, Geophysics, 52, 94-107, 1987.

Honkura, Y., M. Matsushima, N. Oshiman, Y. Sasai, M. Ohno, Y. Tanaka, T. Yamamoto, K. Ikeda, and Y. Wakino, Magnetization structure of the Unzen volcano determined from blimp-borne magnetic survey data, $J$. Geomag. Geoelectr., 47, 231-236, 1995.

Hoshizumi, H., K. Uto, and K. Watanabe, Geology and eruptive history of Unzen volcano, Shimabara Peninsula, Kyushu, SW Japan, J. Volcanol. Geotherm. Res., 89, 81-94, 1999.

Hoshizumi, H., K. Uto, A. Matsumoto, S. Xu, and K. Oguri, Geology of Unzen volcano and core stratigraphy of the flank drillings, Unzen Workshop 2002: International workshop on Unzen Scientific Drilling
Project (USDP), 4-8, 2002.

Makino, M., T. Nakatsuka, R. Morijiri, Y. Okubo, S. Okuma, and Y. Honkura, Derivation of three-dimensional distribution of geomagnetic anomalies from magnetic values at various elevations, Proc. 88th SEGJ Conf., Soc. Explor. Geophys. Japan, 502-507, 1993 (in Japanese).

Mogi, T., Y. Tanaka, T. Morikawa, K. Kusakabe, M. Tanahashi, T. Nakatsuka, K. Tanaka and H. Utada, Subsurface structure of UnzenFugen and Mayu-yama Volcano inferred from airborne electromagnetic method and magnetic survey, Bull. Volcanol. Soc. Japan, 40, 263-276, 1995 (in Japanese with English abstract).

Nakatsuka, T., Reduction of magnetic anomalies to and from an arbitrary surface, Butsuri-Tanko (Geophys. Explor.), 34, 332-339, 1981.

Nakatsuka, T., Aeromagnetic anomalies over the area of Unzendake volcano, J. Geomag. Geoelectr., 46, 529-540, 1994.

Nakatsuka, T., Minimum norm inversion of magnetic anomalies with application to aeromagnetic data in the Tanna area, Central Japan, J. Geomag. Geoelectr., 47, 295-311, 1995.

Nakatsuka, T., Library software for geophysical data processing and representation, Geological Survey Japan Openfile Report, no. 400, 2003.

Okuma, S., Magnetization intensity mapping in and arround Izu-Oshima Volcano, Japan, J. Geomag. Geoelectr., 46, 541-556, 1994.

Okuma, S., Magnetic constraints on the subsurface structure of AkitaYakeyama volcano, northeast Japan, Earth Planets Space, 50, 153-163, 1998.

Ota, K., Unzen volcano. Nagasaki Prefecture, 98 pp., 1984 (in Japanese).

Ozima, M., T. Hashimoto, and Y. Tanaka, Magnetic properties of some volcanics from Mt. Unzen, Abstracts 92nd SGEPSS Fall Meeting, C1204, 1992.

Watanabe, K. and H. Hoshizumi, Geological map of Unzen Volcano, Geological Map of Volcanoes, no. 8, Geol. Surv. Japan, 1995.

A. Okubo (e-mail: ayako@rcep.dpri.kyoto-u.ac.jp), Y. Tanaka, M. Utsugi, N. Kitada, H. Shimizu, and T. Matsushima 